\title{
3-D FEM MODELING OF FIBER/MATRIX INTERFACE DEBONDING IN UD COMPOSITES INCLUDING SURFACE EFFECTS
}

\author{
A.Pupurs, J.Varna \\ Department of Engineering Sciences and Mathematics, Division of Materials Science, Luleå \\ University of Technology, SE 97187, Luleå, Sweden \\ Janis.Varna@1tu.se
}

Fiber/matrix interface debond growth is one of the main mechanisms of damage evolution in unidirectional (UD) polymer composites. Because for polymer composites the fiber strain to failure is smaller than for the matrix multiple fiber breaks occur at random positions when high mechanical stress is applied to the composite. The energy released due to each fiber break is usually larger than necessary for the creation of the fiber break therefore a partial debonding of fiber/matrix interface is typically observed. Thus the stiffness reduction of UD composite is contributed both from the fiber breaks and from the interface debonds.

The aim of this paper is to analyze the debond growth in CF/EP and GF/EP UD composites using fracture mechanics principles by calculation of energy release rate $G_{I I}$. A 3-D FEM model is developed for calculation of energy release rate for fiber/matrix interface debonds at different locations in the composite including the composite surface region where the stress state differs from the one in the bulk composite. For the bulk composite, where the stress state around the fiber break can be approximated as axisymmetric, analytical model developed in [1] was used to calculate $G_{I I}$ for long debonds where the debond growth is self-similar. For the short debond lengths FEM calculations were summarized into a simple mathematical expression to represent the magnification of $G_{I I}$ similarly as in [2].

\section{REFERENCES}

1. A. Pupurs, J. Varna, Mechanics of Advanced Materials and Structures, 2011, Accepted.

2. A.Pupurs, A.Krasnikovs and J.Varna, Mechanics of Advanced Materials and Structures, 2011, Accepted. 